\title{
Salaried Annual Employment
}

National Cancer Institute

\section{Source}

National Cancer Institute. Salaried Annual Employment. NCI Thesaurus. Code C116001.

An employment agreement where the employer pays an arranged amount at a steady yearly interval regardless of hours worked. 